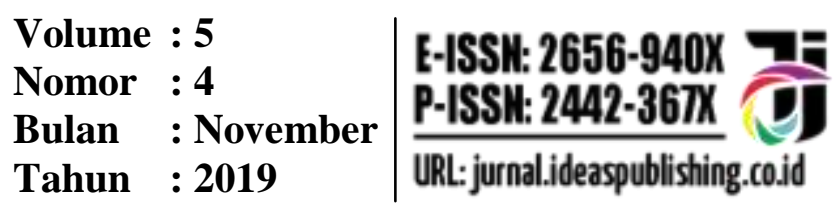

\title{
Model Pembelajaran Teams Games Tournaments (TGT) untuk Meningkatkan Hasil Belajar
}

\author{
Suwarno ${ }^{1}$, Sri Astuti Setiani 2 \\ SMK Negeri 3 Semarang, SMK Negeri 8 Semarang \\ surel: sriastutisetiani@gmail.com \\ DOI: 10.32884 /ideas.v5i4.227
}

\begin{abstract}
Abstrak
Tujuan penelitian ini adalah untuk mengetahui efektivitas model pembelajaran teams games tournament (TGT) untuk meningkatkan kreativitas siswa. Populasi dalam penelitian ini adalah siswa kelas X SMK 8 Semarang Tahun Ajaran 2017/2018. Pemilihan sampel dengan menggunakan random sampling, digunakan kelas X1 sebagai kelas kontrol dan X2 sebagai kelas eksperimen. Kelas eksperimen diajar dengan pembelajaran Teams Games Tournaments (TGT), sedangkan kelas kontrol menggunakan pembelajaran ceramah. Metode pengambilan data dengan dokumentasi data mid semester dan metode tes untuk menentukan hasil belajar siswa yang kemudian dianalisis dengan uji ketuntasan dan uji perbedaan rata-rata. Hasil penelitian adalah hasil belajar siswa kelas eksperimen mencapai ketuntasan belajar lebih baik daripada dengan metode ceramah.
\end{abstract}

Kata kunci: PPKN, Model Pembelajaran, TGT

\section{Pendahuluan}

PPKN merupakan ilmu yang berhubungan dengan perilaku manusia. Setiap guru harus paham terhadap alasan mengapa PPKN perlu diajarkan di sekolah menengah. Ada berbagai alasan yang menyebabkan satu mata pelajaran itu dimasukkan ke dalam kurikulum suatu sekolah. Hasil penelitian menunjukkan bahwa masih banyak permasalahan dalam pelaksanaan standar isi pada mata pelajaran PPKN (Schlesselman et al., 2015). Guru dalam menerapkan pembelajaran lebih menekankan pada metode yang mengaktifkan guru yaitu pembelajaran yang masih menggunakan metode ceramah sehingga pembelajaran kurang optimal dan siswa menjadi kurang aktif dalam mengikuti pembelajaran. Penggunaan metode yang monoton ini dirasa membuat siswa akan merasa bosan dan kurang tertarik terhadap pembelajaran yang dilakukan. Sebagai dampaknya, siswa menjadi kurang aktif dan kurang antusias dalam mengikuti pembelajaran tersebut dan hasil belajar pun kurang maksimal (Cahuc, Shleifer, \& Algan, 2011). 


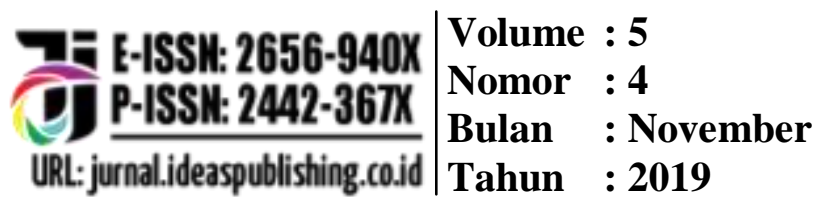

Berdasarkan data yang diperoleh dari hasil observasi dan wawancara di sekolah tempat penelitian, untuk mengefektifkan proses pembelajaran tersebut peneliti telah menetapkan alternatif model pembelajaran yang dapat dipakai untuk mengefektifkan proses pembelajaran. Hal ini dapat mendorong keterlibatan siswa dalam pembelajaran dan meningkatkan kreativitas guru. Oleh karena itu, peneliti menggunakan salah satu model pembelajaran inovatif yaitu model pembelajaran teams games tournament (TGT) (Cahuc et al., 2011). Model pembelajaran ini merupakan salah satu tipe atau model pembelajaran kooperatif yang mudah diterapkan, melibatkan aktivitas seluruh siswa tanpa harus ada perbedaan status, melibatkan peran siswa sebagai tutor sebaya, dan mengandung unsur permainan dan reinforcement. Peneliti menawarkan dalam penelitian ini dengan Teams Games Tournaments (TGT) untuk dapat mengefektifkan kualitas pembelajaran PPKN, meningkatkan hasil belajar siswa, siswa lebih aktif, kreatif, dan terampil sehingga pembelajaran menjadi lebih bermakna, menciptakan peran tutor sebaya, dan guru menjadi lebih kreatif dalam menerapkan model pembelajaran yang inovatif dan menyenangkan.

Pembelajaran diartikan sebagai upaya membuat individu belajar yang dirumuskan Robert W. Gagne (1977) sebagai pengaturan peristiwa yang ada di luar diri seorang peserta didik, dan dirancang serta dimanfaatkan untuk memudahkan proses belajar. Pembelajaran yang mendidik adalah pembelajaran yang menekankan proses membelajarkan peserta didik bagaimana belajar (learning how to learn). Pembelajaran yang mendidik memiliki karakteristik antara lain menekankan proses membelajarkan bagaimana belajar (learning how to learn), mengutamakan strategi yang mendorong dan melancarkan proses belajar peserta didik, diarahkan untuk membantu peserta didik agar berkecakapan mencari jawab atas suatu persoalan atau kecakapan. Bukan menyampaikan informasi langsung kepada peserta didik.

Pembelajaran merupakan upaya membelajarkan siswa (Degeng, 1989). Kegiatan pengupayaan ini akan mengakibatkan siswa dapat mempelajari sesuatu dengan cara efektif dan efisien. Upaya-upaya yang dilakukan dapat berupa analisis tujuan dan karakteristik studi dan siswa, analisis sumber belajar, menetapkan strategi pengorganisasian, isi pembelajaran, menetapkan strategi penyampaian pembelajaran, 


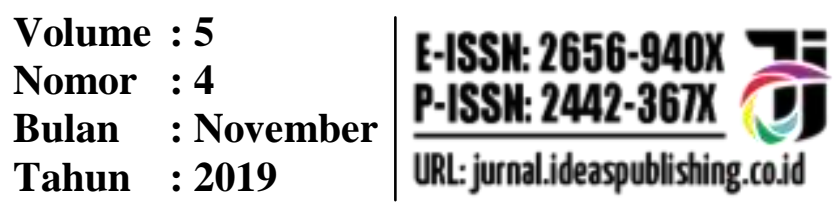

menetapkan strategi pengelolaan pembelajaran, dan menetapkan prosedur pengukuran hasil pembelajaran. Oleh karena itu, setiap pengajar harus memiliki keterampilan dalam memilih strategi pembelajaran untuk setiap jenis kegiatan pembelajaran. Oleh karena itu, dengan memilih strategi pembelajaran yang tepat dalam setiap jenis kegiatan pembelajaran diharapkan pencapaian tujuan belajar dapat terpenuhi. Gilstrap dan Martin (1975) juga menyatakan bahwa peran pengajar lebih erat kaitannya dengan keberhasilan pembelajar, terutama berkenaan dengan kemampuan pengajar dalam menetapkan strategi pembelajaran (Hargreaves, 2010).

Hasil belajar dan mengajar merupakan konsep yang tidak bisa dipisahkan. Belajar merujuk pada apa yang harus dilakukan seseorang sebagai subjek dalam belajar. Sedangkan mengajar merujuk pada apa yang seharusnya dilakukan seseorang guru sebagai pengajar. Dua konsep belajar mengajar yang dilakukan oleh siswa dan guru terpadu dalam satu kegiatan. Di antara keduanya itu terjadi interaksi dengan guru. Kemampuan yang dimiliki siswa dari proses belajar mengajar saja harus mampu mendapatkan hasil, bisa juga melalui kreativitas seseorang itu tanpa adanya intervensi orang lain sebagai pengajar (Mikiewicz, Jonasson, Gudmundsson, Blondal, \& Korczewska, 2011).

Oleh karena itu, hasil belajar yang dimaksud di sini adalah kemampuankemampuan yang dimiliki seorang siswa setelah ia menerima perlakuan dari pengajar (guru). Hal ini seperti yang diungkap oleh Sudjana (2004: 22) bahwa hasil belajar adalah kemampuan-kemampuan yang dimiliki siswa setelah menerima pengalaman belajarnya. Sedangkan menurut Horwart Kingsley dalam bukunya Sudjana membagi tiga macam hasil belajar mengajar, yaitu: (1) keterampilan dan kebiasaan, (2) pengetahuan dan pengarahan, (3) sikap dan cita-cita (Sudjana, 2004: 22). Hasil belajar yang dicapai siswa dipengaruhi oleh dua faktor yakni faktor dari dalam diri siswa dan faktor dari luar diri siswa (Sudjana, 1989: 39). Dari pendapat ini faktor yang dimaksud adalah faktor dalam diri siswa perubahan kemampuan yang dimilikinya seperti yang dikemukakan oleh Clark (1981: 21) bahwa hasil belajar siswa di sekolah 70\% dipengaruhi oleh kemampuan siswa dan 30\% dipengaruhi oleh lingkungan (Flint, 2011). Demikian juga faktor dari luar diri siswa yakni lingkungan yang paling dominan berupa

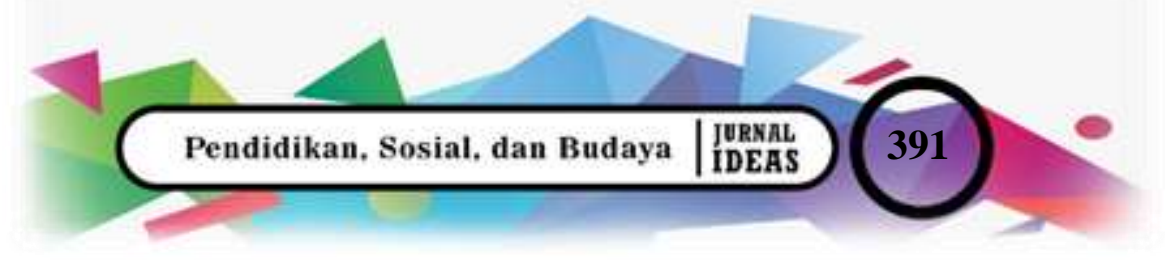




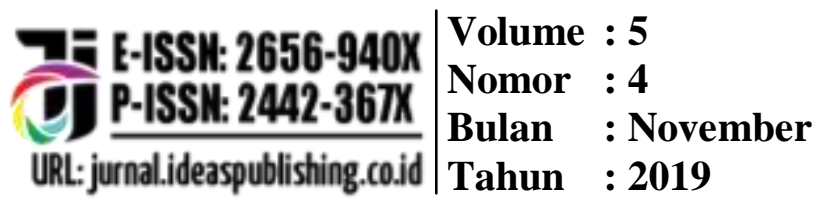

kualitas pembelajaran (Sudjana, 2002: 39). Belajar adalah suatu perubahan perilaku, akibat interaksi dengan lingkungannya (Ali Muhammad, 2004: 14). Perubahan perilaku dalam proses belajar terjadi akibat dari interaksi dengan lingkungan. Interaksi biasanya berlangsung secara sengaja. Dengan demikian, belajar dikatakan berhasil apabila terjadi perubahan dalam diri individu. Sebaliknya apabila tidak terjadi perubahan dalam diri individu, maka belajar tidak dikatakan berhasil. Hasil belajar siswa dipengaruhi oleh kemampuan siswa dan kualitas pengajaran. Kualitas pengajaran yang dimaksud adalah profesional yang dimiliki oleh guru. Artinya, kemampuan dasar guru baik di bidang kognitif (intelektual), bidang sikap (afektif), dan bidang perilaku (psikomotorik).

Pembelajaran kooperatif model TGT adalah salah satu tipe atau model pembelajaran kooperatif yang mudah diterapkan, melibatkan aktivitas seluruh siswa tanpa harus ada perbedaan status, melibatkan peran siswa sebagai tutor sebaya dan mengandung unsur permainan dan reinforcement. Aktivitas belajar dengan permainan yang dirancang dalam pembelajaran kooperatif model TGT memungkinkan siswa dapat belajar lebih rileks di samping menumbuhkan tanggung jawab, kerja sama, persaingan sehat, dan keterlibatan belajar (Catts \& Ozga, 2005).

\section{Metode}

Penelitian ini dilaksanakan di SMK 8 Semarang. Penelitian ini dilakukan selama lima bulan, yaitu dari bulan Agustus sampai Desember 2018. Metode penelitian yang digunakan adalah metode penelitian eksperimen kuantitatif. Desain penelitian yang digunakan adalah desain pola kelompok paralel yang ekuivalen/seharga. Pada eksperimen jenis ini sekaligus dipakai dua kelompok kembar yang ekuivalen (mempunyai nilai, kadar, dan kemampuan yang sama). Pada kelompok yang satu dikenakan variabel-eksperimental, sedangkan pada kelompok lainnya tidak dikenakan. Pada akhir eksperimen diadakan komparasi antara dua kelompok tersebut.

\section{Hasil dan Pembahasan}

Berdasarkan hasil analisis data materi tes tentang kemampuan PPKN bahwa terdapat hubungan layanan Team Games Tournament (TGT) dengan kemampuan 


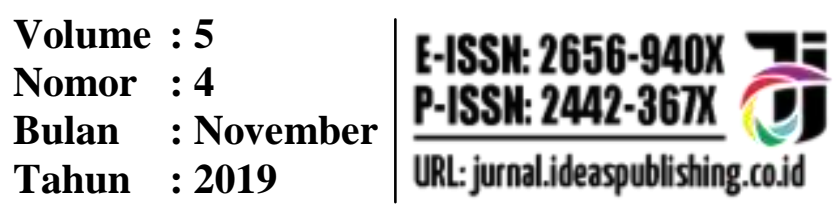

PPKN. Hal tersebut dapat dijelaskan berdasarkan hasil analisis untuk $\mathrm{N}=25$ diperoleh $r_{\text {tabel }}$ sebesar 0,320 dikarenakan $r_{\text {hitung }}$ atau 0,712 $>r_{\text {tabel }}$ maka ada korelasi (hubungan) yang signifikan antara variabel $\mathrm{X}$ dan $\mathrm{Y}$. Berdasarkan perhitungan tersebut, maka hipotesis yang berbunyi hubungan layanan Team Games Tournament (TGT) dengan kemampuan PPKN siswa kelas SMA Negeri 8 Semarang diterima kebenarannya pada taraf signifikan 5\%. Perubahan tersebut dapat terjadi karena dalam pemberian Team Games Tournament (TGT) merupakan sekumpulan individu yang saling berinteraksi dengan tujuan tertentu. Pernyataan tersebut dipertegas oleh Sukamadinata (1999: 3) yaitu klasikal merupakan kesatuan dua atau lebih individu yang saling mengadakan interaksi yang memungkinkan mengadakan interstimulasi dan respon untuk mencapai tujuan bersama. Team games tournament (TGT) adalah bimbingan yang dilaksanakan secara kelompok dalam satu kelas.

Populasi penelitian adalah semua siswa kelas SMK 8 Semarang yang terbagi menjadi 2 kelas, dengan jumlah siswa tiap kelas ada 30 anak. Jadi, semuanya ada $35 \mathrm{x}$ $35=70$ anak. Sampel adalah sebagian dari anggota populasi yang diteliti. Sampel berasal dari populasi yang betul-betul homogen agar sampel representatif atau dapat mewakili populasi. Jadi, sebelum pemilihan sampel dilakukan, dilakukan uji homogenitas dan uji kesamaan rata-rata terhadap populasi. Pengujian homogenitas menggunakan uji Bartlett. Sedangkan uji kesamaan rata-rata dilakukan dengan menggunakan analisis variansi satu arah.

Sampel pada penelitian ini ada dua kelompok yaitu kelompok kontrol dan kelompok eksperimen. Pada penelitian ini, populasi terbagi dalam 2 kelas kemudian 2 kelas tersebut diambil 2 kelas secara acak dengan jumlah siswa sebanyak 70 siswa. Penelitian ini dilakukan dengan teknik sampling yang digunakan yaitu simple random sampling. Teknik ini dilakukan dengan cara pengambilan sampel secara acak dengan kelompok sebagai sasarannya.

Observasi atau disebut juga pengamatan meliputi kegiatan pemusatan perhatian terhadap suatu objek dengan menggunakan seluruh indera (Arikunto, 2002: 133). Metode observasi dalam penelitian ini berisi catatan yang menggambarkan bagaimana aktivitas siswa dalam pembelajaran PPKN dengan menggunakan pembelajaran

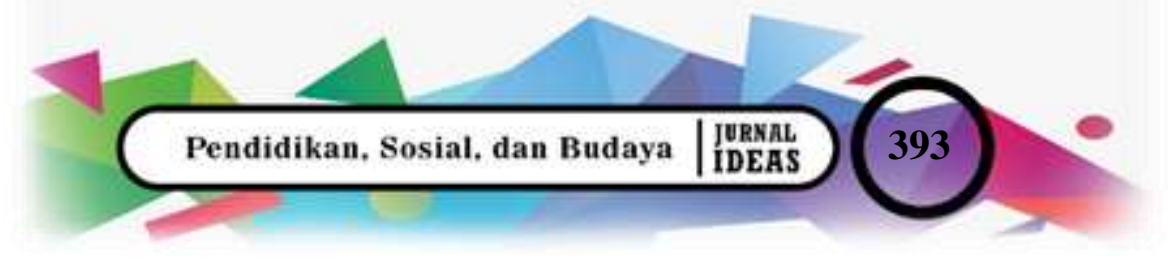




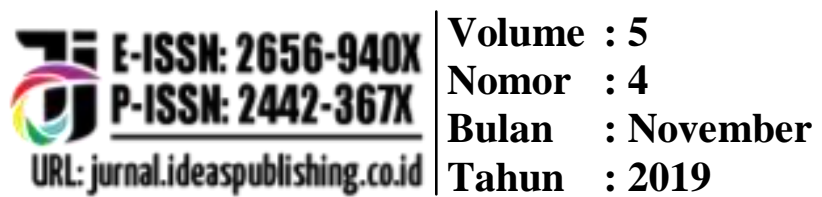

kooperatif tipe Teams Games Tournaments (TGT). Tes adalah serentetan pertanyaan atau latihan serta alat lain yang digunakan untuk mengukur ketrampilan, pengetahuan, intelegensi, kemampuan atau bakat yang dimiliki individu atau kelompok (Arikunto, 2002: 127). Metode tes dalam penelitian ini digunakan untuk mengukur kemampuan dasar dan pencapaian atau prestasi belajar. Tes diberikan kepada siswa secara individu untuk mengetahui kemampuan kognitif siswa. Tes ini dilaksanakan pada pembelajaran siklus I dan siklus II. Metode dokumentasi yaitu mencari data mengenai hal-hal atau variabel yang berupa catatan lapangan, transkrip, buku surat notulen rapat, surat kabar, majalah, prasasti, agenda dan sebagainya (Arikunto, 2002: 206). Metode dokumentasi dilakukan untuk memperkuat data yang diperoleh dalam observasi. Dokumen yang digunakan dalam penelitian ini berupa daftar kelompok siswa dan daftar nilai siswa. Untuk memberikan gambaran secara konkret mengenai kegiatan kelompok siswa dan menggambarkan suasana kelas ketika aktivitas belajar berlangsung digunakan dokumen berupa foto.

Teknik analisis data yang digunakan adalah teknik anava dua jalur dengan variabel bebas berupa mosel pembelajaran TGT dan model pembelajaran konvensional. Dasar pemikiran teknik anava adalah variansi total semua subjek dalam suatu eksperimen dapat dianalisis menjadi dua sumber yaitu varians antarkelompok dan varians dalam kelompok. Anava dua jalur dapat digunakan untuk menguji perbedaan dua mean atau lebih. Penelitian ini menguji perbedaan antara dua kelompok dengan perlakuan dua jenis model pembelajaran. Melalui teknik anava dua jalur dalam penelitian ini, diharapkan dapat menemukan perbedaan dalam pelajaran PPKN yang diberikan dengan model pembelajaran TGT dan model pembelajaran konvensional.

\section{Tabel 1}

\section{Ringkasan Anava Dua Jalur}

\begin{tabular}{|l|l|l|l|l|}
\hline SV & JK & Db & RK & F \\
\hline Antar A & JKA & a-1 & JKA / dbA & RKant/RKdal \\
\hline Antar B & JKB & b-1 & JKB / dbB & RKB / RKdal \\
\hline Interaksi AB & JKAB & dbA X dbB & JKAB / dbAB & RKAB / RKdal \\
\hline Dalam & JKD & N-ab & JKdal / dbdal & \\
\hline Total & JKTOT & N-1 & & \\
\hline
\end{tabular}




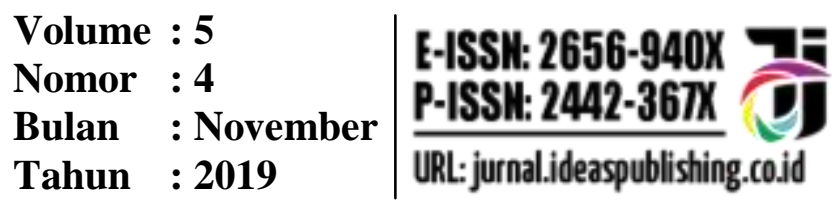

Berdasarkan hasil analisis data materi tes tenatang kemampuan PPKN bahwa terdapat hubungan layanan Team Games Tournament (TGT) dengan kemampuan PPKN hal tersebut dapat dijelaskan berdasarkan hasil analisis untuk $\mathrm{N}=25$ diperoleh $\mathrm{r}_{\text {tabel }}$ sebesar 0,320 dikarenakan $r_{\text {hitung }}$ atau 0,712 $>r_{\text {tabel }}$ maka ada korelasi (hubungan) yang signifikan antara variabel $\mathrm{X}$ dan $\mathrm{Y}$.

\section{Simpulan}

Berdasarkan perhitungan tersebut, maka hipotesis yang berbunyi hubungan layanan Team Games Tournament (TGT) dengan kemampuan PPKN siswa kelas SMA Negeri 8 Semarang diterima kebenarannya pada taraf signifikan 5\%. Perubahan tersebut dapat terjadi karena dalam pemberian Team Games Tournament (TGT) merupakan sekumpulan individu yang saling berinteraksi dengan tujuan tertentu. Pernyataan tersebut dipertegas oleh Sukamadinata (1999: 3) yaitu klasikal merupakan kesatuan dua atau lebih individu yang saling mengadakan interaksi yang memungkinkan mengadakan interstimulasi dan respon untuk mencapai tujuan bersama. Team Games Tournament (TGT) adalah bimbingan yang dilaksanakan secara kelompok dalam satu kelas.

Pembelajaran kooperatif model TGT adalah salah satu tipe atau model pembelajaran kooperatif yang mudah diterapkan, melibatkan aktivitas seluruh siswa tanpa harus ada perbedaan status, melibatkan peran siswa sebagai tutor sebaya, dan mengandung unsur permainan dan reinforcement, maka disarankan agar guru dapat menggunakan model tersebut.

\section{Daftar Pustaka}

Bofota, Y. B., \& Bofota, Y. B. (2013). The impact of social capital on children educational outcomes: the case of Tanzania The impact of social capital on children educational outcomes: The case of Tanzania.

Cahuc, P., Shleifer, A., \& Algan, Y. (2011). Teaching Practices and Social Capital. (6052).

Catts, R., \& Ozga, J. (2005). What is Social Capital and how might it be used in Scotland's Schools? (36).

Flint, N. (2011). Full report Schools, communities and social capital : building blocks in the 'Big Society' Contents.

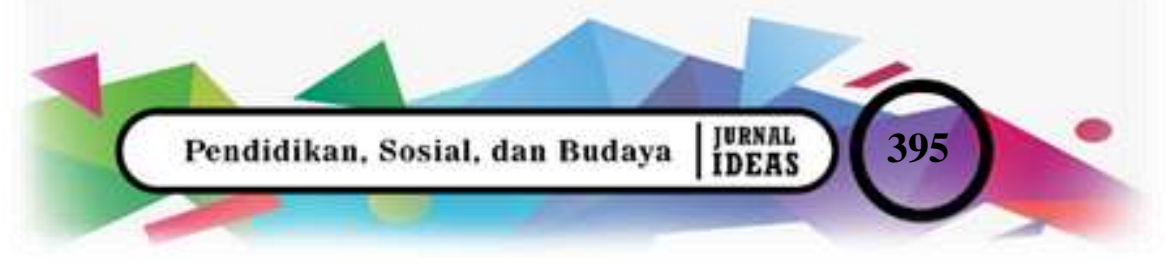




\section{드 E-ISSK: 2656-940X Volume : 5 \\ D] P-ISSK: 2442-367X Nomor : 4 \\ Bulan : November \\ URL: jurnalideaspublishing.co.id Tahun : 2019}

Goddard, R. D. (2016). Relational Networks, Social Trust, and Norms: A Social Capital Perspective on Students 'Chances of Academic Success. 25(1), 59-74.

Depdiknas. (2003). Kurikulum 2004. Jakarta: Depdiknas

Eddy Wibowo, Mungin dkk. (2007). Panduan Penulisan Karya Ilmiah. Semarang: Universitas Negeri Semarang

Endang Poerwanti, dkk. (2008). Asesmen Pembelajaran SD. Jakarta: Direktorat Jendral Pendidikan Tinggi Departemen Pendidikan Nasional.

Hargreaves, A. (2010). School Social Capital and School Effectiveness. 37, 119-136.

Kurnia, Inggridwati. dkk. (2007). Perkembangan belajar peserta didik. Jakarta: Direktorat Jendral Pendidikan Tinggi Departemen Pendidikan Nasional.

Purwanto. M Ngalim. (1997). Psikologi Pendidikan. Bandung: PT Remaja Rosdakarya Siddiq, M. Djauhar. (2008). Pengembangan Bahan Pembelajaran SD. Jakarta: Direktorat Jendral Pendidikan Tinggi Departemen Pendidikan Nasional.

Lash, D., \& Belfiore, G. (2017). 5 Essentials in Building Social Capital Report 4 of the MyWays Student Success Series. (October).

Mikiewicz, P., Jonasson, J. T., Gudmundsson, G., Blondal, K. S., \& Korczewska, D. M. (2011). Comparative research between Poland and Iceland.

Schlesselman, L., Borrego, M., Bloom, T. J., Mehta, B., Drobitch, R. K., \& Smith, T. (2015). An Assessment Of Service-Learning In 34 US Schools Of Pharmacy Follow Up On The 2001 Professional Affairs Committee Report. American Journal of Pharmaceutical Education, 79(8). https://doi.org/10.5688/ajpe798116 